\title{
Herança de caracteres relacionados à produção de frutos em Capsicum baccatum var. pendulum com base em análise dialélica de Hayman $^{1}$
}

\author{
Inheritance of traits related to fruit production in Capsicum baccatum var. pendulum \\ based on Hayman's diallel analysis
}

\author{
Leandro Simões Azeredo Gonçalves ${ }^{2 *}$, Rosana Rodrigues ${ }^{2}$, Cintia dos Santos Bento ${ }^{2}$, Renata Rodrigues Robaina ${ }^{2}$ \\ e Antonio Teixeira do Amaral Júnior²
}

\begin{abstract}
Resumo - Este trabalho teve por objetivo estimar parâmetros genéticos relacionados à produção de frutos em um dialelo de pimenta (Capsicum baccatum var. pendulum). Foram avaliados cinco genitores de pimenta (UENF 1616, UENF 1624, UENF 1629, UENF 1639 e UENF 1732) e seus respectivos híbridos $F_{1}$, a partir de um dialelo completo, sem recíprocos. O experimento foi conduzido em cultivo protegido (politúnel), na área de convênio UENF/PESAGRO-RIO, Campos dos Goytacazes, no período de julho a dezembro de 2009. O delineamento experimental foi em blocos casualizados, com três repetições e nove plantas por parcela. Avaliaram-se as seguintes características agronômicas: diâmetro da copa (DC), altura de planta (ALTP), dias para a frutificação (DF), número de frutos por planta (NFP), peso médio do fruto (PMF), massa seca do fruto (MSF); teor de massa seca (TMS), comprimento do fruto (CF), diâmetro do fruto (DIAM), espessura da polpa (ESP), teor de sólidos solúveis totais (TSS) e produção por planta (PROD). Somente as características PMF, MSF e PROD tiveram ausência de significância nos três testes de suficiência do modelo aditivo-dominante, indicando haver homogeneidade entre as variâncias e covariâncias e, consequentemente, ausência de epistasia no controle destas características. Para PMF e MSF, os efeitos gênicos aditivos foram os mais importantes. Por sua vez, na expressão de PROD o efeito de dominância foi o mais importante. Verificou-se dominância parcial para PMF e MSF e sobredominância para PROD. Os genitores UENF 1616 e UENF 1629 foram os que tiveram as maiores concentrações de alelos favóraveis para as três características em estudo.
\end{abstract}

Palavras-chave - Pimenta. Melhoramento de plantas. Hibridação vegetal. Controle genetico.

\begin{abstract}
This work aimed to estimate genetic parameters related to the fruits production in a chilli pepper diallel (Capsicum baccatum var. pendulum). Five chilli pepper genitors were evaluated (UENF 1616, UENF 1624, UENF 1629, UENF 1639 and UENF 1732) and its respective hybrids $\mathrm{F}_{1}$, from a complete diallel without reciprocals. The experiment was carried out in a greenhouse covered with plastic film located in area from the consortium UENF/PESAGRO-RIO, Campos dos Goytacazes, RJ, from July/2009 to December/2009, in a randomized block design with three repetitions and nine plants by plot. The following agronomic traits were evaluated: canopy diameter (CD); plant height (PH); days for fruiting (DF); number of fruits by plant (NFP); fruit average-weight (FAW); fruit dry mass (FDM); dry matter (DM); fruit length (FL); fruit diameter (FD); fruit wall thickness (PT); total soluble solids (TSS); and yield per plant (PROD). Only the FAW, FDM and PROD had absence of significance concerning the three tests of sufficiency for the additive dominant model, indicating that there is homogeneity among the variances and co-variances and, consequently, lack of epistasis in the control of character. For the FAW and FDM traits, the additive genetic effects were the most important ones. Nevertheless, in the PROD the dominance effect was the most important. It was verified a partial dominance for FAW and FDM, and an over-dominance for PROD. The genitors UENF 1616 and UENF 1629 were the ones which had larger concentrations of favorable alleles for the three characteristics under study.
\end{abstract}

Key words - Chilli pepper. Plant breeding. Plant hybridization. Genetic control.

\footnotetext{
* Autor para correspondência

${ }^{1}$ Recebido para publicação em 20/06/2010; aprovado em 23/04/2011

Parte da Tese de Doutorado do primeiro autor apresentada ao Programa de Pós-Graduação em Genética e Melhoramento de Plantas/UENF

${ }^{2}$ Universidade Estadual do Norte Fluminense Darcy Ribeiro/UENF, Av. Alberto Lamego n. 2.000, Campos dos Goytacazes-RJ, Brasil, 28.013-602,

1sagrural@yahoo.com.br, rosana@uenf.br, cdossantosbento@yahoo.com.br, robainarr@yahoo.com.br, amaraljr@uenf.br
} 


\section{Introdução}

O estudo do controle genético de características quantitativas é de grande relevância para a condução eficiente de um programa de melhoramento de plantas, orientando na escolha dos melhores procedimentos de seleção e dos métodos mais eficientes na condução das populações segregantes (CRUZ et al., 2004; KHAN et al., 2009; LÉDO et al., 2001; SCHUELTER et al., 2010; SILVA et al., 2004). Para tanto, os cruzamentos dialélicos são bastante eficientes devido à geração de informações valiosas para o melhorista como, por exemplo, escolha de genitores para hibridação, identificação de métodos mais eficientes de seleção e conhecimentos das bases genéticas que controlam as características (CRUZ et al., 2004; NASCIMENTO et al., 2010; POLETINE et al., 2006; RÊGO et al., 2009).

Entre os métodos de análise dialélica, Cruz et al. (2004) mencionam como principais as propostas por Griffing (1956), pela qual são estimados os efeitos da capacidade geral e especifica de combinação; Gardner e Ebehart (1966), na qual são avaliados os efeitos variedade e heterose varietal; e o método proposto por Hayman (1954), que gera informações sobre os mecanismos básicos de herança da característica em estudo.

O método de Hayman (1954) se fundamenta no conhecimento da natureza ambiental e genética de estatísticas (médias, variâncias e covariâncias), obtida a partir de uma tabela dialélica que fornece informações sobre o grau médio de dominância da característica, distribuição de alelos entre genitores, limite teórico de seleção, relação entre alelos favoráveis e dominância, proporção entre genes dominantes e recessivos e coeficientes de determinação genotípica (CRUZ et al., 2004; LÉDO et al., 2001; SILVA et al., 2004; SILVA et al., 2010). Entretanto, as restrições do modelo genético-estatístico, como por exemplo: i) segregação diplóide; ii) genitores homozigotos; iii) ausência de efeito materno; iv) ausência de alelismo múltiplo; v) genes distribuídos independentemente, e vi) ausência de epistasia são obstáculos para a utilização desta metodologia pelos pesquisadores (CRUZ et al., 2004; SCHUELTER et al., 2010; SILVA et al., 2010).

Em olerícolas, alguns autores vêm utilizando esta metodologia para incrementar informações em diversos caracteres quantitativos de interesse como, por exemplo, em tomate (AMARAL JÚNIOR et al., 1999; HAZRA; ANSARY, 2008; MALUF et al., 1982; MIRANDA et al., 1982; SCHUELTER et al., 2000), alface (LÉDO et al., 2001) e pimentão/ pimenta (PATIL; SALIMATH, 2008; SCHUELTER et al., 2010; SOUZA; MALUF, 2003; XUE-XIAO et al., 2007). No caso mais específico das pimentas, Souza e Maluf (2003), avaliando os componentes genéticos das características produção total, relação comprimento/diâmetro do fruto, massa seca de fruto por planta, incidência de Xanthomonas campestris pv. vesicatoria, rendimento de capsaicina por planta e número de sementes por fruto em cinco genitores e 10 híbridos de $C$. chinense, constataram a importância e predominância de efeitos gênicos não aditivos para todos os caracteres avaliados. Os autores também evidenciaram importante efeito de epistasia para massa seca de frutos por planta, rendimento de capsaicina por planta e número de sementes por fruto.

Apesar da importância econômica e nutricional do gênero Capsicum e dos inúmeros estudos com dialelo em hortaliças de modo geral, pouca informação tem sido encontrada na literatura com análise dialélica em cruzamentos envolvendo C. baccatum var. pendulum, uma espécie promissora no que diz respeito ao consumo de seus frutos, tanto in natura, em molhos e saladas, quanto para a indústria alimentícia. O presente trabalho teve como objetivo determinar o controle genético de alguns caracteres agronômicos importantes em um dialelo com cinco genitores de C. baccatum var. pendulum, com o propósito de obter informações sobre a herança de características de interesse comercial para auxiliar no desenvolvimento de programas de melhoramento com a espécie.

\section{Material e métodos}

Foram utilizados cinco acessos de Capsicum baccatum var. pendulum do Banco de Germoplasma da Universidade Estadual do Norte Fluminense Darcy Ribeiro (UENF) identificados por UENF 1616, UENF 1624, UENF 1629, UENF 1639 e UENF 1732. Os cruzamentos envolvendo os cinco genitores foram realizados em esquema de dialelo completo, sem recíprocos, obtendo-se um total de 10 híbridos. As hibridações foram realizadas em condições de casa de vegetação, localizada na Unidade de Apoio à Pesquisa (UAP) da UENF, utilizando-se oito vasos por genitor, cada um contendo uma planta, sendo os cruzamentos realizados entre os meses de abril a junho de 2008 .

Para a realização dos cruzamentos, botões florais recém-abertos de cada um dos genitores masculinos foram coletados para retirada do pólen. O pólen obtido de cada genitor foi armazenado em geladeira, dentro de recipientes contendo sílica-gel, devidamente identificados. Os botões florais das plantas dos cinco genitores femininos foram emasculados pela manhã, antes da antese, utilizando-se uma pinça. No mesmo 
período, a polinização foi feita colocando-se grãos de pólen de cada um dos genitores masculinos nos estigmas de cada flor emasculada. Fios de lã de cores diferentes foram utilizados para identificar os frutos oriundos de cada diferente tipo de cruzamento.

Para avaliação das características agronômicas, os híbridos e os genitores foram cultivados em estrutura protegida, do tipo politúnel, na área de convênio da UENF com Empresa de Pesquisa Agropecuária do Estado do Rio de Janeiro (PESAGRO-RIO), Estação Experimental de Campos, em Campos dos Goytacazes, RJ. O delineamento experimental foi em blocos ao acaso com três repetições e nove plantas por parcela. $\mathrm{O}$ espaçamento foi de $1,0 \times 0,9 \mathrm{~m}$ entre fileiras e plantas. A temperatura média variou de 21 a $28{ }^{\circ} \mathrm{C}$ durante o período do experimento.

Durante a condução do experimento, foram efetuados os tratos culturais normalmente recomendados para a cultura (FILGUEIRA, 2005) como capinas, tutoramento, adubação e irrigação pelo sistema de microaspersão. As características agronômicas avaliadas foram: diâmetro da copa (DC), em cm; altura de planta (ALTP), em cm; dias para a frutificação (DF); número de frutos por planta (NFP); peso médio do fruto (PMF), em g; massa seca do fruto (MSF), em g; teor de massa seca (TMS), em \%; comprimento do fruto (CF), em mm; diâmetro do fruto (DIAM), em mm; espessura da polpa (ESP), em mm; teor de sólidos solúveis totais (TSS), em ${ }^{\circ}$ BRIX; e produção por planta (PROD), em kg planta ${ }^{-1}$.

Para o estudo da herança das características agronômicas, utilizou-se a metodologia de Hayman (1954), avaliando-se o grau médio de dominância, a distribuição dos alelos entre os genitores, o limite teórico de seleção, a relação entre alelos favoráveis e dominância, o número de genes que exibem dominância, a proporção entre genes dominantes e recessivos, e o coeficiente de determinação genotípico. Todas as análises genético-estatísticas foram realizadas pelo programa Genes (CRUZ, 2006).

\section{Resultados e discussão}

Em todos os caracteres estudados, houve significância do efeito genótipos (cultivares + respectivos híbridos $\mathrm{F}_{1}$ ) pelo teste $\mathrm{F}$. Os coeficientes de variação experimental (\%) obtidos em DF, TMS (\%), COMP, TSS, ALTP, ESP, DIAM, DC, MSF, PMF, PROD e NFP foram de 2,$06 ; 6,46 ; 7,86 ; 8,01$; 9,$65 ; 10,01 ; 10,29 ; 11,81 ; 13,80 ; 15,80 ; 23,90$ e 24,17, respectivamente. Estes resultados refletem uma precisão experimental, garantindo a validade das conclusões inferidas. Assim, procedeu-se à análise dialélica de cada caráter, segundo o método proposto por Hayman (1954).

Para aplicação deste método, é necessária a aplicação de testes de suficiência do modelo aditivodominante, com base na heterogeneidade $\hat{W}_{r}-\hat{V}_{r}$. Na Tabela 1, são apresentados os resultados da aplicação de três testes na avaliação da adequação dos dados ao modelo aditivo-dominante dos caracteres avaliados. Os caracteres PMF, MSF e PROD tiveram ausência de significância nos três testes, indicando haver homogeneidade entre as variâncias e covâriancias, estando em conformidade com as restrições impostas e a viabilidade de utilização do modelo aditivodominante. Nos demais caracteres, a ocorrência de significância em pelo menos um dos testes do modelo aditivo-dominante evidenciou a não adequação das pressuposições para utilização da metodologia de Hayman (1954) e, portanto, foram excluídos da análise.

\section{Peso médio do fruto (PMF)}

$\mathrm{Na}$ Tabela 2 observam-se as correlações entre o valor genotípico do i-ésimo genitor $\left(\bar{Y}_{i i}\right)$ e a soma da covariância e variância entre médias da i-ésima linha $\left(\hat{W}_{i}\right.$ e $\left.\hat{V}_{i}\right)$, bem como os valores esperados das coordenadas $\left(V_{R}, W_{R}, \hat{W}_{D}\right.$ e $\left.\hat{V}_{D}\right)$ e da soma delas. Ao se avaliar a característica PMF, observa-se que houve correlação negativa entre $\left(\bar{Y}_{i \mathrm{i}}\right)$ e $\left(\hat{W}_{i}\right.$ e $\left.\hat{V}_{i}\right)$ de $-0,6632$, evidenciando que os alelos dominantes, em sua maioria, são responsáveis pelo aumento médio do peso do fruto. A ordem dos genitores, em relação à concentração de alelos dominantes, é UENF 1616, UENF 1629, UENF 1732, UENF 1639 e UENF 1624 (TAB 3, FIG 1).

A Figura 1a evidencia a possibilidade de obtenção de segregantes ainda mais dominantes para PMF, o que pode ser constatado pelo fato de que o genitor UENF 1616, embora seja o de maior concentração de alelos dominantes, com o valor de $\hat{W}_{R}+\hat{V}_{R}=30,4602$ (TAB. 3), ainda é inferior ao que se pode alcançar, ou seja, 8,3703 (TAB. 2).

Com relação às estimativas dos componentes genéticos (TAB. 4), constata-se que para PMF há predomínio dos componentes associados aos efeitos aditivos $(\widetilde{D})$ em relação aos componentes associados aos efeitos de dominância $\left(\widetilde{H}_{1}, \widetilde{H}_{2}\right.$ e $\left.\tilde{h}^{2}\right)$, denotando potencial de ganhos pela obtenção de segregantes superiores. A oportunidade de obtenção destes segregantes torna-se mais concreta em virtude do valor do coeficiente de determinação de 0,6862 , no sentido restrito $\left(\tilde{h}^{2}\right)$ (TAB. 5), ser de uma magnitude suficiente para concluir pela fidedignidade da transmissão dos alelos desejáveis a futuras gerações. 

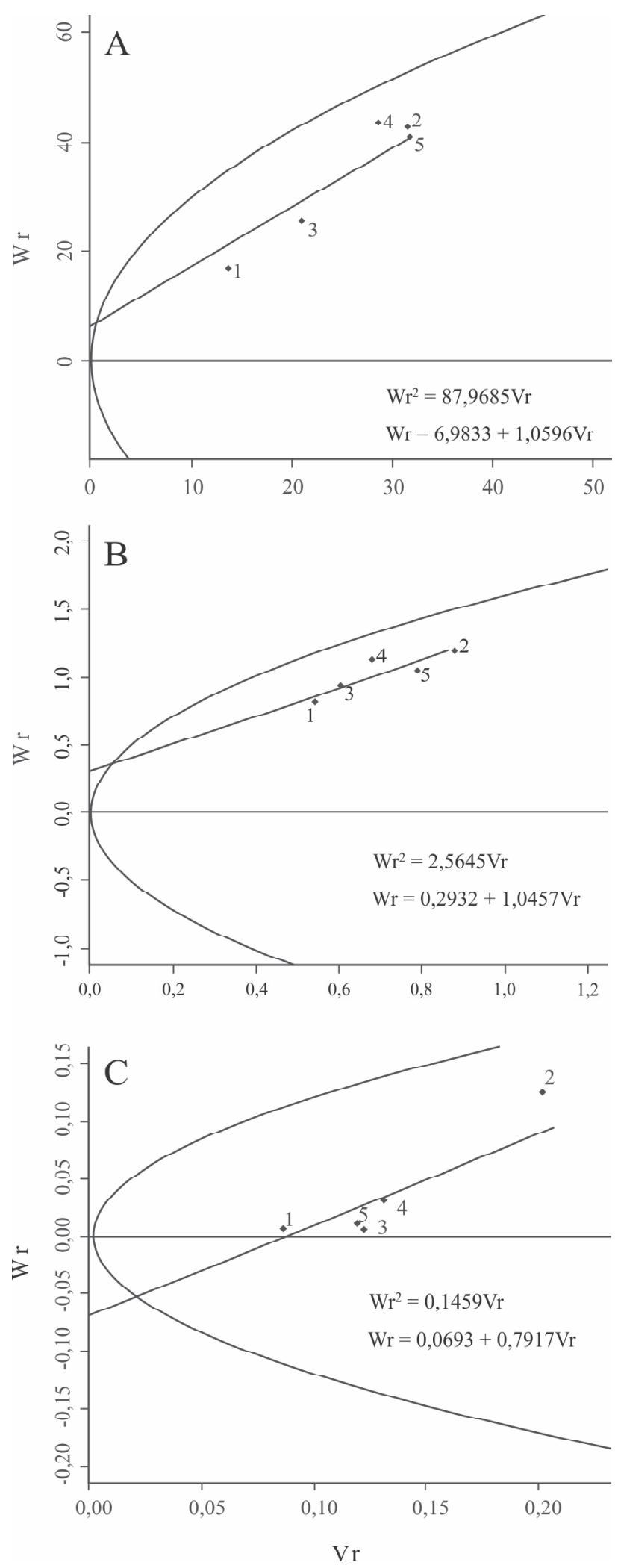

Figura 1 - Regressões de $\hat{W}_{R}$ em $\hat{V}_{R}$ das características: (a) Peso médio do fruto $(\mathrm{g}),(\mathbf{b})$ massa seca do fruto $(\mathrm{g}) \mathrm{e}(\mathbf{c})$ produtividade $\left(\mathrm{kg} \mathrm{planta}^{-1}\right) .1=$ UENF 1616, $2=$ UENF 1624, 3 = UENF 1629, $4=$ UENF 1732 e $5=$ UENF 1639
Esse resultado está em consonância com os obtidos por Gomide et al. (2003) que, ao avaliarem a capacidade de combinação de linhagens elite de pimentão (Capsicum annuum L.), também verificaram a importância dos efeitos gênicos aditivos na expressão de PMF. Vale ressaltar que os trabalhos realizados com dialelo em Capsicum no Brasil, não obstante serem raros, têm-se concentrado, quase exclusivamente, nos cruzamentos entre variedades de pimentões (SOUZA; MALUF, 2003). Em relação à espécie C. baccatum, a maioria dos estudos está voltada para condições de pré-melhoramento (SUDRÉ et al., 2005; SUDRÉ et al., 2010). Porém, essa situação tende a mudar, sobretudo devido ao interesse dos produtores por novos genótipos que atendam às exigências de maior produtividade, uniformidade e qualidade dos frutos, associadas à resistência a doenças de diversas etiologias, como o mosaico amarelo do pimentão, causado pelo Pepper Yellow Mosaic Vírus, e a mancha-bacteriana, causada por Xanthomonas euvesicatoria, e para as quais já foi observada resistência em germoplasma de C. baccatum (BENTO et al. 2009; SUDRÉ, 2003).

O valor 0,3251 do grau médio de dominância $\left(\sqrt{\widetilde{H}_{l}} / \widetilde{D}\right)$ indica a existência de dominância parcial entre os alelos que atuam no controle gênico do PMF (TAB. 5), o que é verificado também pelo fato da reta de regressão de $\hat{W}_{R}$ em $\hat{V}_{R}$ interceptar a ordenada acima da origem (FIG. 1A).

A simetria alélica pode ser confirmada quando o produto da frequência dos alelos favoráveis e desfavoráveis $\left(\mathrm{u}_{\mathrm{t}}, \mathrm{v}_{\mathrm{t}}\right)$ assumir valores próximos a 0,25 , com $\mathrm{w}_{\mathrm{t}}=0$, bem como a estimativa $\widetilde{K}_{D} / \widetilde{K}_{R}$ apresentar magnitudes próximas à unidade. Considerando-se que

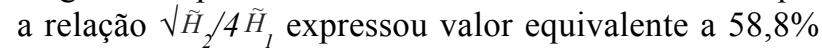
de 0,25 e que $\widetilde{K}_{D} / \widetilde{K}_{R}$ revelou estimativas superiores à unidade, não se pode inferir sobre a ocorrência de simetria alélica absoluta entre os genitores.

\section{Massa seca do Fruto (MSF)}

Os resultados obtidos para a MSF foram semelhantes aos obtidos para PMF, tendo uma correlação negativa entre $\left(\bar{Y}_{i j}\right)$ e $\left(\hat{W}_{i}\right.$ e $\left.\hat{V}_{i}\right)$, com magnitude de $-0,7909$, evidenciando que os alelos dominantes, em sua maioria, são responsáveis pelo aumento da massa seca do fruto, e que o genitor UENF 1616 teve a maior concentração de alelos dominantes, seguidos pelos genitores UENF 1629, UENF 1732, UENF 1639 e UENF 1624 (TAB. 2 e 3).

Os efeitos aditivos também foram preponderantes sobre os de dominância em razão do valor 2,0963 na relação $\widetilde{D}-\widetilde{H}_{l}$ (TAB. 4). A dominância parcial é a interação prevalecente, em decorrência do valor 0,3079 registrado pelo estimador $\sqrt{ } \widetilde{H}_{1} / \widetilde{D}$, o que também pode ser constatado 
Tabela 1 - Teste de suficiência do modelo genético aditivo-dominante com base na análise de variância dos valores $\hat{W}_{r}-\hat{V}_{r}$. e na análise de regressão linear de $\hat{W}_{i}$, em função de $\hat{W}_{r}$, segundo o método de Hayman (1954). Campos dos Goytacazes, RJ

\begin{tabular}{|c|c|c|c|c|}
\hline \multirow{2}{*}{ Caráter $^{1 /}$} & \multirow{2}{*}{$\frac{\text { Anova } \hat{W}_{r}-\hat{V}_{r}}{\text { QM Linhas }}$} & \multicolumn{3}{|c|}{ Regressão $\left[\hat{W}_{r}=1 / 4\left(\hat{D}-\hat{H}_{I}\right)+\mathrm{b} \hat{V}_{r} \cdot\right]$} \\
\hline & & $\mathrm{b} \pm$ Variância & $t\left(H_{0}: b=1\right)$ & $\mathrm{F}=\mathrm{t}^{2}\left(\mathrm{H}_{\mathrm{o}} \mathrm{b}^{\prime}=0\right)^{2 /}$ \\
\hline $\mathrm{DC}$ & $8290,9769 * *$ & $0,9577 \pm 0,0116$ & $-0,6460^{\mathrm{ns}}$ & $-0,3167^{\mathrm{ns}}$ \\
\hline ALTP & $4564,5830 * *$ & $0,9775 \pm 0,0108$ & $-5,4265^{* *}$ & $2,1975^{\mathrm{ns}}$ \\
\hline DF & $25,9645^{\mathrm{ns}}$ & $0,5597 \pm 0,0098$ & $-4,4356^{* *}$ & $2,8140^{*}$ \\
\hline NFP & $286735,91^{\mathrm{ns}}$ & $0,4107 \pm 0,0285$ & $-4,8357 * *$ & $2,0859^{\mathrm{ns}}$ \\
\hline PMF & $69,7798^{\mathrm{ns}}$ & $0,8090 \pm 0,0603$ & $-0,7778^{\mathrm{ns}}$ & $-0,8922^{\mathrm{ns}}$ \\
\hline MSF & $0,0257^{\mathrm{ns}}$ & $0,8965 \pm 0,0347$ & $-0,5554^{\mathrm{ns}}$ & $-0,6840^{\text {ns }}$ \\
\hline TMS(\%) & $0,9383^{\mathrm{ns}}$ & $0,1824 \pm 0,0442$ & $-5,6233 * *$ & $0,9317^{\mathrm{ns}}$ \\
\hline COMP & $5763,3389^{*}$ & $0,8254 \pm 0,0118$ & $-1,6043^{\mathrm{ns}}$ & $0,7568^{\mathrm{ns}}$ \\
\hline DIAM & $609,8747^{*}$ & $0,6964 \pm 0,0109$ & $-2,9111^{*}$ & $1,7913^{\mathrm{ns}}$ \\
\hline ESP & $0,0036 \mathrm{~s}$ & $0,4493 \pm 0,0135$ & $-4,7340 * *$ & $2,6742 *$ \\
\hline TSS & $0,1548 *$ & $0,7752 \pm 0,0257$ & $-1,4015^{\mathrm{ns}}$ & $0,2015^{\mathrm{ns}}$ \\
\hline PROD & $0,0011^{\mathrm{ns}}$ & $0,6156 \pm 0,0597$ & $-1,5735^{\mathrm{ns}}$ & $-0,3168^{\mathrm{ns}}$ \\
\hline
\end{tabular}

${ }_{1}^{1} \mathrm{DC}=$ diâmetro da copa $(\mathrm{cm}) ; \mathrm{ALTP}=$ altura da planta $(\mathrm{cm}) ; \mathrm{DF}=$ dias para frutificação; $\mathrm{NFP}=$ número de frutos por planta; $\mathrm{PMF}=$ peso médio do fruto $(\mathrm{g}) ; \mathrm{MSF}=$ massa seca do fruto $(\mathrm{g})$; TMS = teor de matéria seca $(\%)$; COMP = comprimento do fruto $(\mathrm{mm})$; DIAM = diâmetro do fruto $(\mathrm{mm}) ;$ ESP = esnessura da polpa $(\mathrm{mm})$; TSS = teor de sólidos solúveis totais (\%); e PROD = produtividade $\left(\mathrm{kg}\right.$ planta $\left.{ }^{-1}\right) .{ }^{2}$ Teste $\mathrm{F}$, ponderando os valores médios de $\hat{W}_{r}$ $-\hat{V}_{r}$, por meio de sua rotação de $45^{\circ}$. ns Não-significativo "e ${ }^{* * *}$ significativo ao nível de $5 \%$ e $1 \%$, respectivamente, pelo teste $\mathrm{F}$ e pelo teste $\mathrm{t}$

Tabela 2 - Estimativas das correlações entre o valor genotípico do i-ésimo genitor $\left(\bar{Y}_{i i}\right)$ e a soma da covariância com a variância entre médias da i-ésima linha $\left(\hat{W}_{i}+\hat{V}_{i}\right)$, assim como os valores esperados das coordenadas $\hat{V}_{R}, \hat{W}_{R}, \hat{W}_{D}$ e $\hat{V}_{D}$ e da soma destas para três características avaliadas em cinco genitores de Capsicum baccatum var. pendulum, segundo a metodologia de Hayman (1954). Campos dos Goytacazes, RJ

\begin{tabular}{|c|c|c|c|c|c|c|c|}
\hline \multirow{2}{*}{ Cárater } & \multicolumn{7}{|c|}{ Estimativas dos parâmetros } \\
\hline & $\mathrm{r}\left(\bar{Y}_{i i}, \hat{W}_{i} \mathrm{e} \hat{V}_{i}\right)$ & $\hat{W}_{R}$ & $\hat{V}_{R}$ & $\hat{W}_{R}+\hat{V}_{R}$ & $\hat{W}_{D}$ & $\hat{V}_{D}$ & $\hat{W}_{D}+\hat{V}_{D}$ \\
\hline PMF & $-0,6632$ & 75,3238 & 64,4967 & 139,8205 & 7,6969 & 0,6734 & 8,3703 \\
\hline MSF & $-0,7909$ & 2,1120 & 1,7392 & 3,8512 & 0,3405 & 0,0452 & 0,3857 \\
\hline PROD & $-0,9813$ & 0,2380 & 0,3882 & 0,6262 & $-0,0537$ & 0,0197 & $-0,034$ \\
\hline
\end{tabular}

${ }_{1}^{1 /} \mathrm{PMF}=$ peso médio do fruto $(\mathrm{g}) ; \mathrm{MSF}=$ massa seca do fruto $(\mathrm{g})$; e $\mathrm{PROD}=$ produtividade $\left(\mathrm{kg} \mathrm{planta}^{-1}\right)$

Tabela 3 - Valores da soma da covariância entre média dos genitores e médias da i-ésima linha $\left(\hat{W}_{R}\right)$ e da variância entre médias da j-ésima linha $\left(\hat{V}_{R}\right)$ para três características avaliadas em cinco genitores de Capsicum baccatum var. pendulum, segundo a metodologia de Hayman (1954). Campos dos Goytacazes, RJ

\begin{tabular}{|c|c|c|c|c|c|c|}
\hline \multirow{3}{*}{ Genótipos } & \multicolumn{6}{|c|}{ Características Agronômicas ${ }^{1 / 1}$} \\
\hline & \multicolumn{2}{|r|}{ PMF } & \multicolumn{2}{|r|}{ MSF } & \multicolumn{2}{|r|}{ PROD } \\
\hline & $\hat{W}_{R}+\hat{V}_{R}$ & Média (g planta-1) & $\hat{W}_{R}+\hat{V}_{R}$ & Média $\left(\mathrm{g}\right.$ planta $\left.{ }^{-1}\right)$ & $\hat{W}_{R}+\hat{V}_{R}$ & Média $\left(\mathrm{kg}\right.$ planta $\left.{ }^{-1}\right)$ \\
\hline UENF 1616 & 30,4602 & 24,2480 & 1,3599 & 3,9607 & 0,0929 & 1,2333 \\
\hline UENF 1624 & 74,2405 & 9,3578 & 2,0673 & 1,4400 & 0,3268 & 0,554 \\
\hline UENF 1629 & 46,4977 & 28,0560 & 1,5417 & 4,7920 & 0,1284 & 1,0563 \\
\hline UENF 1732 & 72,1824 & 12,6413 & 1,8081 & 2,0927 & 0,1620 & 0,9440 \\
\hline UENF 1639 & 72,7051 & 23,5413 & 1,8354 & 3,8307 & 0,1309 & 1,1883 \\
\hline
\end{tabular}

${ }^{1 / \mathrm{PMF}}=$ peso médio do fruto $(\mathrm{g}) ; \mathrm{MSF}=$ massa seca do fruto $(\mathrm{g})$; e $\mathrm{PROD}=$ produtividade $\left(\mathrm{kg} \mathrm{planta}^{-1}\right)$ 
Tabela 4 - Estimativas dos componentes genéticos e não-genéticos de quatro características agronômicas, segundo o método de Hayman (1954). Campos dos Goytacazes, RJ

\begin{tabular}{crrrrrrc}
\hline \multirow{2}{*}{ Caráter $^{1 /}$} & \multicolumn{7}{c}{ Componente $^{2 /}$} \\
\cline { 2 - 8 } & \multicolumn{1}{c}{$\widetilde{c}$} & \multicolumn{1}{c}{$\widetilde{c}$} & $\widetilde{H}_{1}$ & $\widetilde{H}_{2}$ & $\widetilde{h}^{2}$ & $\widetilde{F}^{2}$ & $D-\widetilde{H}_{1}$ \\
\hline PMF & 10,9152 & 77,0532 & 8,1455 & 4,7917 & 9,2034 & 27,4147 & 68,9077 \\
MSF & 0,2486 & 2,3159 & 0,2195 & 0,0814 & 0,0690 & 0,7353 & 2,0963 \\
PROD & 0,0873 & 0,0586 & 0,1668 & 0,1548 & 0,2280 & 0,0446 & $-0,1082$ \\
\hline
\end{tabular}

${ }^{1}$ PMF = peso médio do fruto $(\mathrm{g}) ; \mathrm{MSF}=$ massa seca do fruto $(\mathrm{g})$; TSS = teor de sólidos solúveis totais $(\%) ;$ e PROD = produtividade $\left(\mathrm{kg}\right.$ planta $\left.{ }^{-1}\right) ;$ 2/ $\widetilde{\varepsilon}$ = componente de variância ambiental; $\widetilde{D}=$ componente de variância associado aos efeitos aditivos; $\widetilde{H}{ }_{1}$ e $\widetilde{H}_{2}=$ componentes de variância associados aos desvios de dominância; $\widetilde{h}^{2}=$ componente quadrático determinado pela diferença de média entre híbridos e pais; $\widetilde{F}=$ componente associado à covâriancia entre efeitos aditivos e não-aditivos; e $\widetilde{D}-\widetilde{H}_{1}=$ componente que expressa à diferença entre efeitos gênicos aditivos e dominantes

Tabela 5 - Estimativas dos parâmetros genéticos e não-genéticos de três características agronômicas, segundo o método de Hayman (1954). Campos dos Goytacazes, RJ

\begin{tabular}{ccccccc}
\hline \multirow{2}{*}{ Caráter $^{1 /}$} & \multicolumn{5}{c}{ Estimativas dos parâmetros ${ }^{2 /}$} \\
\cline { 2 - 7 } & ${\sqrt{H} \widetilde{H}_{I} / \widetilde{D}}^{\text {PMF }}$ & $\sqrt{ } \widetilde{H}_{2} / 4 \widetilde{H}_{1}$ & $\widetilde{K}_{D} / \widetilde{K}_{R}$ & $\widetilde{h}_{2} / \widetilde{H}_{2}$ & $\tilde{h}_{R}{ }_{R}$ & $\tilde{h}_{A}{ }_{A}$ \\
MSF & 0,3251 & 0,1470 & 3,4163 & 1,9207 & 0,6862 & 0,7173 \\
PROD & 1,6875 & 0,0923 & 3,1291 & 0,8475 & 0,7616 & 0,7796 \\
\hline
\end{tabular}

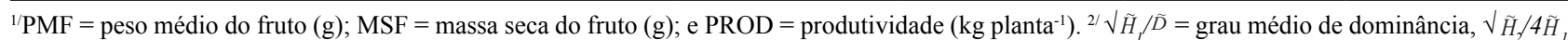
= distância dos alelos - simetria, $\widetilde{K}_{D} / \widetilde{K}_{R}=$ relação dominante/recessivo, $\widetilde{h}_{2} / H_{2}=$ número de genes com dominância, $\widetilde{h}_{R}^{2}=$ coeficiente de determinação no sentido restrito, e $\widetilde{h}_{A}{ }_{A}=$ coeficiente de determinação no sentido amplo

pela Figura 1b, na qual a linha de regressão corta o eixo $\hat{W}_{R}$ acima da origem. A distribuição dos alelos entre os genitores não é simétrica, dado o valor obtido de $\sqrt{ } \widetilde{H}_{2} / 4 \widetilde{H}_{1}$ ser igual a 0,0923 e evidenciado, também, pela relação média do número de genes dominantes e recessivos de 3,1291, sendo os alelos dominantes predominantes entre os genitores (TAB. 5).

Os coeficientes de determinação genotípica, restrito e amplo, foram 0,7616 e 0,7796 , respectivamente (TAB. 5). Essas estimativas foram inferiores aos obtidos por Rêgo (2001) que observou, para massa seca do fruto, em sete genótipos de C. baccatum var. pendulum, valores de 0,84 e 0,98 para determinação genotípica restrita e ampla, respectivamente. Entretanto, a mesma autora verificou, para as respectivas características dominância parcial e efeitos aditivos preponderantes, resultados que estão de acordo com o presente trabalho.

\section{Produção por planta (PROD)}

A elevada correlação entre $\bar{Y}_{i i}$ e $\hat{W}_{i}+\hat{V}_{i}$, com valor estimado de $-0,9813$ (TAB. 2), demonstra que os genes dominantes contribuem, em sua maioria, para aumentos na característica. A ordem dos genitores, em relação à concentração de alelos dominantes é UENF 1616, UENF 1629, UENF 1639, UENF 1732 e UENF 1624 (TAB. 3), com destaque para o genitor UENF 1616, cujo valor de $\hat{W}_{R}$ $+\hat{V}_{R}$ é de 0,0929. Contudo esse valor ainda é inferior ao extremo dominante da regressão de $\hat{W}_{i}$ sobre $\hat{V}_{i}$ (FIG. 1C), com limite de seleção de -0,034 (TAB. 2).

Na Tabela 4, evidencia-se a predominância dos efeitos de dominância, haja vista a superioridade das estimativas $\widetilde{H}_{1}, \widetilde{H}_{2}$ e $\tilde{h}_{2}^{2}$ em comparação à estimativa associada a efeitos aditivos $(D)$. Do mesmo modo, a magnitude negativa para $\widetilde{D}-\widetilde{H}_{1}(-0,1082)$ revela que os efeitos de dominância são mais importantes na expressão da característica. O valor de 1,6875 para estimativa do grau médio de dominância denota que a interação intra-alélica é sobredominante, o que é verificado também pelo fato de a reta de regressão $\hat{W}_{R}$ em $\hat{V}_{R}$ interceptar a ordenada abaixo da origem (TAB. 5 e FIG. 1C). Com este resultado, pode-se supor que o uso comercial de híbridos com alta capacidade produtiva é uma alternativa viável em termos de produção.

Rêgo et al. (2009), ao avaliarem a capacidade geral e específica de combinação de oito acessos de $C$. baccatum var. pendulum para componentes de produção (altura de planta, diâmetro da copa entre plantas, diâmetro da copa entre fileiras, altura da primeira bifurcação, número de frutos por planta e produção), verificaram que os efeitos não aditivos (dominância ou epistasia) foram 
os mais importantes no controle dessas características. Em relação à característica produção, o resultado está em consonância com o obtido por Zambrano et al. (2005) que verificaram predomínio de efeitos não-aditivos sobre os efeitos aditivos em C. annuum. Assim, pode-se inferir que os resultados obtidos por Rêgo et al. (2009) e Zambrano et al. (2005) também foram semelhantes aos observados no presente trabalho, ainda que o background genético tenha sido diferente.

A distribuição dos alelos entre os genitores foi simétrica, dado o valor obtido de simetria igual a 0,2320 e evidenciado, também, pela relação média do número de genes dominantes e recessivos $\left(\widetilde{K}_{D} / \widetilde{K}_{R}=1,5819\right)$, embora haja uma ligeira predominância de alelos dominantes. A reduzida magnitude da herdabilidade no sentido restrito denota pouca confiabilidade dos genótipos em transmitir o fenótipo desejável aos descendentes. Isto indica que, no caso de se optar pela obtenção de cultivares formadas por linhas puras, os métodos de melhoramento mais complexos como a seleção recorrente, que mantém a variabilidade e aumenta o desempenho da população ao longo das gerações de recombinação, ou os métodos mais simples, baseados na seleção em gerações mais avançadas, quando então já houve a fixação dos caracteres de interesse, como o Single Seed Descent (SSD), podem ser recomendados para a obtenção de ganhos satisfatórios em termos de produção de frutos por planta em gerações futuras.

\section{Conclusões}

1. Apenas as características peso médio do fruto (PMF), massa seca do fruto (MSF) e produção por planta (PROD) se adequaram às restrições impostas à viabilidade de utilização do modelo aditivo-dominante proposto por Hayman;

2. A variação de natureza aditiva contribuiu para o controle gênico nas características PMF e MSF, enquanto, para produção de plantas, os efeitos gênicos de dominância são os mais importantes;

3. Detectou-se dominancia parcial para PMF e MSF e sobredominância para PROD;

4. UENF 1616 e UENF 1629 tiveram maior concentração de alelos favoráveis para as três características em estudo.

\section{Agradecimentos}

Os autores agradecem à Coordenação de Aperfeiçoamento de Pessoal de Nível Superior (CAPES), pela concessão da bolsa de doutorado ao primeiro autor.

\section{Referências}

AMARAL JÚNIOR, A. T. et al. Inferências genéticas na produção e qualidade de tomateiro sob cruzamento dialélico. Pesquisa Agropecuária Brasileira, v. 34, n. 08, p. 1407 1416, 1999.

BENTO, C. S. et al. Sources of resistance againt the Pepper yellow mosaic virus in chili pepper. Horticultura Brasileira, v. 27, n. 02, p. 196-201, 2009.

CRUZ, C. D. Programa Genes: biometria. Viçosa: Imprensa Universitária, 2006. 480 p.

CRUZ, C. D. et al. Modelos biométricos aplicados ao melhoramento genético. Viçosa: UFV, 2004.480 p. v. 3.

EL-BRAMAWY, M. A. S. et al. Inheritance of yield, yield components and resistance to major diseases in Sesamum indicum L. Spanish Journal of Agricultural Research, v. 06, n. 04, p. 623-628, 2008.

FILGUEIRA, F.A. Novo manual de olericultura: Agrotecnologia moderna na produção e comercialização de hortaliças. Viçosa: UFV, 2005. 412 p.

GARDNER, C. O.; EBEHART, S. A. Analysis and interpretation of the variety cross diallel and related populations. Biometrics, v. 22, n. 18, p. $439-452,1966$.

GOMIDE, M. L. et al. Heterose e capacidade combinatória de linhagens de pimentão (Capsicum annuum L.). Ciência e Agrotecnologia, v. 27, n. 05, p. 1007-1015, 2003.

GRIFFING, B. Concept of general and especific combining ability in relation to diallel crossing systems. Australian Journal of Biological Sciences, v. 09, n. 04, p. 463-493, 1956.

HAYMAN, B. I. The theory and analysis of diallel crosses. Genetics, v. 39, n. 04, p. 789-809, 1954.

HAZRA, P.; ANSARY, H. Genetics of heat tolerance for floral and fruit set to high temperature stress in tomato (Lycopersicon esculentum Mill). Sabrao Journal of Breeding and Genetics, v. 40, n. 02 , p. $117-125,2008$.

KHAN, N. U. et al. Diallel analysis of some quantitative traits in Gossypium hirsutum L. Pakistan Journal of Botanic, v. 41, n. 06, p. 3009-3022, 2009.

LÉDO, F. J. S. et al. Análise genética em um dialelo de alface. Pesquisa Agropecuária Brasileira, v. 36, n. 03, p. 493-499, 2001.

MALUF, W. R. et al. Análise genética de um cruzamento dialélico de cultivares de tomate. I. Características referentes à produção de frutos. Pesquisa Agropecuária Brasileira, v. 17, n. 04 , p. 633-641, 1982.

MIRANDA, J. E. C. et al. Análise genética de um cruzamento dialélico de cultivares de tomate. II Características vegetativas. Pesquisa Agropecuária Brasileira, v. 17, n. 05, p. 767-773, 1982.

NASCIMENTO, I. R. et al. Capacidade combinatória de linhagens de pimentão a partir de análise dialélica multivariada. Acta Scientiarum Agronomy, v. 32, n. 02, p. 235-240, 2010. 
PATIL, S. S. A. et al. Estimation of gene effects for fruit yield and its components in chili (Capsicum annuum L.). Karnataka Journal of Agricultural Science, v. 21, n. 02, p. 181-183, 2008.

POLETINE, J. P. et al. Inferências genéticas em cultivares diferenciadoras de feijoeiro comum ao Colletotrichum lindemuthianum raça 69. Semina: Ciências Agrárias, v. 27, n. 03, p. 393-398, 2006.

RÊGO, E. R. Diversidade, herança e capacidade combinatória em pimenta (Capsicum baccatum). 2001. 117 f. Tese (Doutorado em Genética e Melhoramento) Universidade Federal de Viçosa, Viçosa.

RÊGO, E. R. et al. A diallel study of yield components and fruit quality in chilli pepper (Capsicum baccatum). Euphytica, v. 168, n. 02, p. 275-287, 2009.

SCHUELTER, A. R. et al. Genetic analysis of tomato accessions with pleiotropic genes affecting postharvest attributes. Acta Scientiarum, v. 22, n. 04, p. 861-868, 2000.

SCHUELTER, A. R. et al. Genetic control of agronomically important traits of pepper fruits analyzed by Hayman's partial diallel cross scheme. Genetics and Molecular Research, v. 09, n. 01, p. 113-127, 2010.

SILVA, M. P. et al. Genetic control n morphoagronomic traits in snap bean. Brazilian Archives of Biology and Technology, v. 47, n. 06, p. 855-862, 2004.
SILVA, V. Q. R. et al. Inheritance for economically important traits in popcorn from distinct heterotic groups by Hayman's diallel. Cereal Research Comunications, v. 38, n. 02, p. 272-284, 2010.

SOUZA, J. A.; MALUF, W. R. Diallel analyses and estimation of genetic parameters of hot pepper (Capsicum chinense Jacq.). Scientia Agricola, v. 60, n. 01, p. 105-113, 2003.

SUDRÉ, C. P. Divergência genética e avaliação da resistência à mancha bacteriana em Capsicum spp. 2003. 112 f. Dissertação (Mestrado em Produção Vegetal) - Universidade Estadual do Norte Fluminense Darcy Ribeiro, Campos dos Goytacazes.

SUDRÉ, C. P. et al. Divergência genética entre acessos de pimenta e pimentão utilizando técnicas multivariadas. Horticultura Brasileira, v. 23, n. 01, p.22-27, 2005.

SUDRÉ, C. P. et al. Genetic variability in domesticated Capsicum spp as assessed by morphological and agronomic data in mixed statistical analysis. Genetics and Molecular Research, v. 09, n. 01, p. 283-294, 2010.

XUE-XIAO, Z. et al. Hayman genetic analysis of yield and quality characters in pepper (Capsicum annuum L.). Acta Horticulturae Sinica, v. 34, n. 03, p. 623-628, 2007.

ZAMBRANO, G. M. et al. Efectos genéticos y heterosis en la vida de anaquel del chile serrano. Revista Fitotecnia Mexicana, v. 28 , n. 04 , p. 327-332, 2005. 